\title{
Parents' views on preparation to care for extremely premature infants at home
}

\author{
Julia Petty, Lisa Whiting, Janet Green et al
}

\section{Citation}

Petty J, Whiting L, Green J et al (2018) Parents' views on preparation to care for extremely premature infants at home. Nursing Children and Young People. doi: 10.7748/ncyp.2018.e1084

\section{Peer review}

This article has been subject to open peer review and checked for plagiarism using automated software

\section{Correspondence}

J.Petty@herts.ac.uk

\section{Conflict of interest}

This study was funded by the University of Hertfordshire, England

\section{Acknowledgement}

The authors are grateful to parents who participated in this study and gatekeepers from the local trust who assisted with recruitment

\section{Accepted \\ 24 April 2018}

\section{Published online}

June 2018

For related information, visit nursingchildrenandyoung people.co.uk and search using the keywords

\begin{abstract}
Aim To gain insight into the post-discharge experiences of parents in relation to the adequacy of preparation for caring for extremely premature infants at home.

Method A narrative approach was drawn on to facilitate data collection, through face-to-face semi-structured interviews with 14 parents of extremely premature infants.

Findings Constant comparative analysis was used to allow the emergence of five key research themes - emotional and mental health of parents, uncertain outcomes, ongoing health needs of the baby, educational needs of health professionals, and parental support and preparation for transition home.

Conclusion Parental experience of being discharged home with a premature baby can be emotionally challenging and necessitates a range of support mechanisms to help them to cope with this period of transition. Health professionals can direct parents to appropriate counselling services, resources and peer support groups. Tailored education is needed for community-based health professionals, such as health visitors, to equip them to support parents practically and emotionally during the transition home and beyond. In addition, health professionals can learn much from parents about what is needed to support them.
\end{abstract}

\author{
Author details \\ Julia Petty, senior lecturer in children's nursing, department of nursing and social work, University of \\ Hertfordshire, England; Lisa Whiting, professional lead children's nursing, University of Hertfordshire, \\ Hertfordshire, England; Janet Green, senior lecturer, University of Technology Sydney, New South \\ Wales, Australia; Cathrine Fowler, professor, University of Technology Sydney, New South Wales, \\ Australia
}

\section{Keywords}

babies, child health, fathers, intensive care, mothers, neonatal, parents

\section{Introduction}

While survival of extremely premature babies has increased in the past 20 years, the potential for significant morbidity continues including lifelong disabilities (Galeano and Carvajal 2016) as well as developmental and behavioural problems later in life (Whittingham et al 2014). Globally, more than one in ten pregnancies end in preterm birth. In the UK each year, approximately 60,000 babies are born prematurely (World Health Organization 2012, 2018), 7\% of all live births (Office for National Statistics 2017).

These figures highlight the importance of nurses and the multidisciplinary team in addressing the specific needs of premature babies and their parents. Parents are faced with caring for these vulnerable babies with specific ongoing challenges after discharge into the community. This article reports on the findings of a study that explored the experiences of parents with very premature babies in relation to their transition home and thereafter. The terms 'baby' and 'infant' are used interchangeably throughout the article.

\section{Background}

Parenting premature babies after discharge from neonatal care has been described as challenging, time consuming, socially disruptive and requiring increased professional (Boykova 2016a) and ongoing community support (Staniszewska et al 2012, Ingram et al 2016). Questions remain about how best to prepare and support parents in caring for their infants after discharge.

Extreme prematurity, in the context of this study, was defined as a gestational age of 30 weeks or less at birth. Being born this early can be a crisis for babies and their families, 
who experience a highly technological, overwhelming and unfamiliar journey through the neonatal intensive care unit (NICU). As discharge approaches, parents can become apprehensive and question their ability to care for their baby without the NICU technology and staff.

With increased survival of extremely premature babies, questions have emerged about the adequacy of preparation for transition to the home environment, especially given the high rate of re-hospitalisations (Galeano and Carvajal 2016). A comprehensive and coordinated approach to transition (Jefferies 2014) can help parents emerge from their NICU experience with increased competence and confidence in infant caregiving (Jefferies 2014). However, there is evidence that families do not always feel adequately prepared to take their baby home (Sneath 2009, Boykova 2016b). Poor discharge planning has the potential to worsen outcomes for the high-risk and vulnerable infant who may have ongoing medical needs (Smith et al 2009).

\section{Aim}

The aim of this study was to gain insight into the post-discharge experiences of parents in relation to the adequacy of preparation for caring for their extremely premature infant at home. In turn, it was hoped that the findings would increase awareness and understanding of the resources and support that are required by the parents of extremely premature infants, before discharge and in the community setting, to inform services.

\section{Method}

Narrative inquiry is an interpretive methodological approach within the broader field of qualitative research (Riessman and Speedy 2007). Narrative inquiry focuses on how individuals make sense of something and their individual perceptions of it (Squire et al 2014). In the context of this research, the inquiry studied the narratives of parents of extremely premature infants. Purposive sampling was chosen to recruit parents, a method used widely in qualitative research and drawn on as it facilitates the identification of 'informationrich' participants (Palinkas et al 2015). The participants sought were parents whose infants had been born at 30 weeks' gestation or less and who had been discharged home within the previous one to six years.

To reuse this article or for information about reprints and permissions, please contact permissions@rcni.com
Data collection

The research team were 'blinded' to the selection of participants, with information

about the research being disseminated by a third party. Once ethical approval had been granted, the coordinator of an NHS trustbased parent support group, located in south east England, liaised with parents and invited them to participate in the study. Details of interested participants were forwarded to the research team and a mutually convenient date and time was arranged to conduct a semistructured interview with the parent(s) in their own home. Interviews with seven participants were undertaken between September and November 2017 and lasted between 46 and 72 minutes. To gain further insight, secondary data analysis was undertaken on another seven transcripts that had been generated after interviews with parents, also in their own homes, between February 2016 and January 2017. These interviews lasted between 60 and 110 minutes and focused on the parent's story about having a premature baby (Petty 2017).

\section{Data analysis}

While the constant comparative analysis method is central to grounded theory (Glaser and Strauss 1967, Strauss 1987, Glaser 1992), it is also fundamental to other areas of qualitative research (Hewitt-Taylor 2001, Boeije 2002), with coding being key to the process (Offredy and Vickers 2010). Boeije (2002) suggests that there are potentially five different levels of comparison. This study involved three of them: " Comparison within a single interview.

» Comparison between interviews within the same group.

॥ Comparison of interviews from different groups (the primary and secondary interview transcripts).

The three stages of coding identified by Strauss and Corbin (1998) - open, axial and selective - were drawn on to facilitate the analysis of the interview transcripts and the emergence of the themes. All data analysis was undertaken by the same member of the research team and then independently verified by another.

\section{Ethical considerations}

Ethical approval for the study was granted by the Health Research Authority (Research Ethics Committee Reference 17/YH/0161), as well as the University of Hertfordshire for the secondary data analysis. Written consent was obtained before the interviews, and all were digitally recorded and were undertaken by the same researcher to maintain consistency.

\section{Findings}

Analysis of the transcripts of 14 interviews (Table 1) revealed five key themes - emotional 
and mental health of parents, uncertain outcomes, ongoing health needs of the baby, educational needs of health professionals, and parental support and preparation for transition home.

Emotional and mental health of parents Participants expressed mixed feelings about going home with their babies. Some felt joy and excitement while others expressed nervousness and fear at the thought of caring for their babies alone, away from the support pillars of the NICU. Some participants said they had simultaneous positive and negative feelings:

'Suddenly you are alone... it felt good to bring him home, of course that is what anyone wants, but it was nerve-racking' (interview 5).

'Even though we wanted to come home... then you think your world falls apart really. Things are a lot harder to deal with, things that you would normally be okay with' (secondary data 2).

Even if discharge preparation was deemed to be good, a consistent finding throughout the interviews was the emotional effect of the experience at home. Reports of intense emotional reactions were evident, which continued into the first few years after discharge:

'It has been a huge emotional upheaval... you cannot ignore it or dismiss it... The emotional support and understanding of what that person has been through needs attention' (interview 2).

'I was experiencing anxiety and panic attacks... it was quite an overwhelming situation of bringing him home' (interview 4).

'I had this really strange turn... diagnosed with post-traumatic stress, and that was a year down the line' (secondary data 3 ).

Participants reported a state of hypervigilance, a feeling of not being able to leave their baby, hindering opportunities to socialise:

'So coming home there was the constant fear that something was going to happen to him... not sleeping and watching him constantly and checking him every three hours' (interview 1).

'It was not until she was four months that I began to kind of relax a bit and actually take her out and start doing things' (interview 3).

In addition, participants talked about a sense of relief in being able to finally care for their baby - it had been like a form of 'suspended parenting', attributed by some to lack of early bonding. They also often found that suddenly having to care for their baby alone was a daunting experience:

'I do feel if... in that first month you have been separated from your mother and you are nursed in a tiny box and people do horrible things to you, I think it must have an effect' (secondary data 6).

'Once I came home we were kind of left on our own... you have spent so much time in a unit where you feel like you are borrowing your own baby... but then you have gone from that where you kind of feel like you have to ask for permission to hold your baby... to being at home' (interview 7).

\section{Uncertain outcomes}

Brain injury and/or bleeds and the potential effect of these on the babies' future were a concern for some participants. The uncertainty of the outcome was a cause of anxiety adding to the emotional challenges already highlighted:

'It is horrible being scared to death... it is devastating them saying "He might have to have a shunt, he might have brain damage" all those things, horrible, horrible' (interview 5).

'I still do not know why it happened... Would we end up with a disabled child?' (secondary data 1 ).

\section{Ongoing health needs of the baby}

Continuing health issues were reported in all of the interviews, especially relating to gastrooesophageal reflux and chronic lung problems. Re-hospitalisations for these problems occurred for most participants and frequent follow-up appointments also presented challenges including practical and financial difficulties, placing an extra strain on their emotional well-being:

'The first year I found hard because I had postnatal depression and he had very severe reflux, so we had quite a difficult first year' (interview 4).

'We were probably up the hospital every week... then at least one appointment every fortnight... it is not only expensive but that is a lot of appointments to cope with' (interview 1).

Education needs of health professionals Community health professionals were perceived to lack knowledge about caring for parents of premature babies. The participants felt there needed to be more focused training and knowledge about the specific differences and needs of premature babies so they could be better supported in the community:

'I would like to see better parent support from GPs, from consultants, from health

\section{Key points}

- Parents face practical, financial and emotional challenges when returning home from hospital with a premature baby and no longer having the support of the neonatal intensive care unit

- Healthcare staff should create a climate where the feelings of parents are considered individually and promote strategies to enhance the emotional closeness between parent and baby in the early days

- Communitybased healthcare professionals, such as health visitors, need to be equipped to support parents practically and emotionally, and to signpost them to counselling and resources including peer support groups 
visitors, a better understanding' (interview 2).

'There is a real lack of understanding about premature babies out there' (secondary data 2).

\section{Parental support and preparation for transition home}

Preparation for discharge by the neonatal staff was deemed to be appropriate. In fact, neonatal staff were praised and highly valued. A range of strategies were used to prepare participants to care for their baby at home, including resuscitation training, parentcraft and the opportunity to stay with their babies overnight.

Exceptions to the many positive reports of good preparation came from those who thought that it was too late or was rushed, making them feel unprepared for the transition home. Even those who regarded the preparation as good felt they needed continuing support services. The emotional effects of going home were, for example, reflected in the counselling services used by some participants:

\begin{tabular}{|c|c|c|c|c|c|}
\hline Interview label & $\begin{array}{l}\text { Gender } \\
\text { of child }\end{array}$ & Age of child & $\begin{array}{l}\text { Gestation of child } \\
\text { at birth (in weeks) }\end{array}$ & $\begin{array}{l}\text { Birth } \\
\text { weight }\end{array}$ & $\begin{array}{l}\text { Parent(s) } \\
\text { interviewed }\end{array}$ \\
\hline \multicolumn{6}{|l|}{ Interviews } \\
\hline 1 & M & Four years & $24+$ two days & $0.72 \mathrm{~kg}$ & Mother \\
\hline 2 & M & Four years & 28 & $1 \mathrm{~kg}$ & Father \\
\hline 3 & $F$ & Four years & $29+$ three days & $1.4 \mathrm{~kg}$ & Mother \\
\hline 4 & M & Three years & 30 & $1.6 \mathrm{~kg}$ & Mother \\
\hline 5 & M & Two years & $28+$ six days & $1.2 \mathrm{~kg}$ & Mother and father \\
\hline 6 & M & 14 months & 27 & $1 \mathrm{~kg}$ & Mother \\
\hline 7 & M & Five years & 28 & $1.25 \mathrm{~kg}$ & Mother \\
\hline \multicolumn{6}{|l|}{ Secondary data } \\
\hline 1 & M & One year & 30 & $1.36 \mathrm{~kg}$ & Mother \\
\hline 2 & $\mathrm{~F}$ & Three years & 24 & $0.7 \mathrm{~kg}$ & Mother \\
\hline 3 & M & Six years & 30 & $1.1 \mathrm{~kg}$ & Mother \\
\hline 4 & M & Five years & 29 & $1 \mathrm{~kg}$ & Mother \\
\hline 5 & $\mathrm{~F}$ & Six years & 24 & $0.615 \mathrm{~kg}$ & Mother \\
\hline 6 & M & Four years & 24 & $0.75 \mathrm{~kg}$ & Mother \\
\hline 7 & $\mathrm{~F}$ & Two years & 24 & $0.9 \mathrm{~kg}$ & Mother \\
\hline
\end{tabular}

'I had counselling to talk about what had happened to try and help with the anxiety and panic attacks... we were going through what happened bit by bit and kind of breaking down how I feel about it' (interview 4).

'I went into a bit of a depression... it was not postnatal depression as such, more the effect of everything... they were really supportive, got me some counselling, so that was good' (interview 6).

Participants stressed the importance of assistance from other parents during difficult times in making them feel less isolated and serving as a source of emotional peer support after discharge. Some also recognised that giving birth prematurely prevented them from joining peer groups attended by parents with healthy, full-term babies:

'There is this thing about feeling institutionalised and sometimes a feeling of isolation. We had missed out on all that National Childbirth Trust and so on... It is a whole set of people that I have not had that journey with' (secondary data 5).

Finally, one area of support identified as being essential was for feeding, emphasising how it can pose a significant challenge for parents with resultant emotional effects:

'Before you release the mum and baby, make sure they are in a proper pattern... I should have continued expressing and then I would have had more milk... there was no specialist support for feeding' (secondary data 4).

'So really breastfeeding was my salvation... There is a group run by mums to support you with breastfeeding... it is really good and it makes all the difference' (secondary data 7).

\section{Discussion}

This study identified factors requiring further exploration to improve the experiences of parents of preterm babies. While there is a substantial body of evidence about the physical development of this group of babies (Roberts and Cheong 2014, Walsh et al 2017), the emotional experience of parents in the years after discharge home is a relatively new area. This study adds further perspectives to work already in existence.

Studies have reported on the immediate stressors of having a baby in the neonatal unit, the anxieties of being separated from the baby directly after birth and feelings of disconnection (Grosik et al 2013). Sisson et al (2015) found high levels of anxiety and stress in parents, which were thought to contribute to feeling less confident in the parental role. However, there is a need to consider these issues on an ongoing basis after babies have 
gone home. Korja et al (2012) explored the longer-term effects of these early experiences in the first two years post-discharge and found they persisted for the first six months. This present study agreed with those findings, but provides evidence that the challenges associated with having a preterm baby can continue for up to six years after discharge.

The lack of role as a parent is another emotional issue. Spinelli et al (2016) found that mothers on a neonatal unit reported an inability to feel they had a mothering role, concurring with the 'suspended parenting' concept identified in this study. Our findings also support the conclusions of an integrative literature review by Adama et al (2016), who explored parents' experiences of caring for preterm infants after discharge from NICU. They concluded that this process requires support to enhance confidence and address the challenges of caring, which can be complicated by overprotective parenting.

Areas for development in terms of emotional care, highlighted in other research, were also noted in our study. Toral-López et al (2016) reported that parents of premature babies felt improvements were needed in the support they received for the emotional aspects of their experience, along with information provided. Franck et al (2017) analysed secondary interview data and concurred with Toral-López et al (2016) that parents of premature babies experienced emotional challenges at home.

Compared with the findings of previous work, while much is in common, this study focuses on the ongoing need for support for a specific group of parents, it also adds another dimension. Participants identified three points of advice for parents in a similar position: the importance of getting to know other parents, asking for emotional help and making the best use of the support services offered. A strong theme in this study, which other work has not specifically reported on, was parents learning from and supporting each other.

\section{Limitations}

The limitations of the study should be acknowledged. Overall, it was conducted in south east England and so the views of the parents may not be reflective of opinions in other areas of the UK. Due to the voluntary nature of recruitment the researchers had no control over the ethnic background, age or gender of the participants. They compromised mainly mothers between the ages of 30 to 40 from a Caucasian ethnicity rather than representing a range of different characteristics.
However, the value of the father's participation was valued. In addition, the interviews were conducted largely in the participants' own homes. While this provided a familiar and comfortable setting, there were distractions at times which could have influenced the data collection.

\section{Implications for practice}

The findings enable a better understanding of what parents of this vulnerable group of babies need for the transition home, leading to some key implications for practice. Parents face specific challenges after discharge with their premature baby including practical, financial and emotional difficulties, all of which mutually influence each other. The need for emotional support warrants further investigation in relation to what is required in practice when working with parents. Flacking et al (2016) proposed that healthcare staff should create a climate where parents' emotional journeys are considered individually and promote strategies to enhance the emotional closeness between parent and baby in the early days so that it continues in the months and years that follow. Examples are the facilitation of early, close proximity and enabling central involvement in their baby's care, all of which influence confidence in caring for their babies in the future (Radenkovic et al 2016).

There is a need for health professionals to provide specific strategies to support parents faced with difficult situations such as signposting them to appropriate counselling services, and resources and help including peer support groups and contacts, which were found to be a significant help.

This study also highlights the need to provide tailored education for communitybased healthcare professionals, such as health visitors, to better equip them to support parents practically and emotionally during the period of transition home and beyond. In addition, healthcare professionals can learn much from parents about what is needed to support them in the transition home. The study by Franck et al (2017) outlines recommendations from parents on how professionals can best support them in areas such as provision of feeding advice and specific education in relation to prematurity.

These implications will lead to future work focusing, for example, on consultation with health professionals to examine their specific knowledge base in relation to discharge planning and parental support strategies. Further exploration of parental perspectives, 
embracing those from more diverse cultural and ethnic backgrounds, as well as more fathers, would help.

\section{Conclusion}

The experience of being discharged home with a premature baby can be emotionally challenging for parents, necessitating a range of support mechanisms. While parents can anticipate going home to be a positive and exciting event, it also means they no longer have the close support received during their stay in the NICU. This can be daunting and unsettling for the family and can last for a long time. This study has highlighted parents' experiences of the transition home and what it is like for them after discharge so that their needs can be better understood and adequate preparation and support can be provided.

\section{References}

Adama E, Bayes S, Sundin D (2016) Parents experiences of caring for preterm infants after discharge from neonatal intensive care unit: a meta-synthesis of the literature. Journal of Neonatal Nursing. 22, 1, 27-51.

Boeije H (2002) A purposeful approach to constant comparative method in the analysis of qualitative interviews. Quality and Quantity. 36, 4, 391-409.

Boykova M (2016a) Life after discharge: what parents of preterm infants say about their transition to home. Newborn and Infant Nursing Reviews. $16,2,58-65$.

Boykova M (2016b) Transition from hospital to home in parents of preterm infants: a literature review. The Journal of Perinatal \& Neonatal Nursing $30,4,327-348$

Flacking R, Thomson G, Axelin A (2016) Pathways to emotional closeness in neonatal units: a crossnational qualitative study. BMC Pregnancy and Childbirth. 16,1,170.

Franck L, McNulty A, Alderdice F (2017) The perinatal-neonatal care journey for parents of preterm infants: what is working and what can be improved. The Journal of Perinatal \& Neonatal Nursing. 31, 3, 244-255

Galeano M, Carvajal B (2016) Coping in mothers of premature newborns after hospital discharge Newborn and Infant Nursing Reviews. 16, 3, 105-109.

Glaser B (1992) Emergence Vs Forcing: Basics of Grounded Theory Analysis. Sociology Press, Mill Valley CA.

Glaser B, Strauss A (1967) The Discovery of Grounded Theory: Strategies for Qualitative

\section{Research. Aldine Publishing, New York NY}

Grosik C, Snyder D, Cleary G et al (2013) Identification of internal and external stressors in parents of newborns in intensive care. The Permanente Journal. 17,3,36-41.

Hewitt-Taylor J (2001) Use of constant comparative analysis in qualitative research. Nursing Standard. $15,42,39-42$.

Ingram J, Powell J, Blair P et al (2016) Does familycentred neonatal discharge planning reduce healthcare usage? A before and after study in South West England. BMJ Open. 6, 3, e010752.

Jefferies A (2014) Going home: facilitating discharge of the preterm infant. Paediatrics and Child Health. $19,1,31-42$

Korja R, Latva R, Lehtonen L (2012) The effects of preterm birth on mother-infant interaction and attachment during the infant's first two years. Acta Obstetricia et Gynecologica Scandinavica. 91,2, 164-173.

Office for National Statistics (2017) Pregnancy and Ethnic Factors Influencing Births and Infant Mortality: 2014. ONS, Newport.

Offredy M, Vickers $P$ (2010) Developing a Healthcare Research Proposal. An Interactive Student Guide. Wiley-Blackwell, Chichester

Palinkas L, Horwitz S, Green C et al (2015) Purposeful sampling for qualitative data collection and analysis in mixed method implementatio research. Administration and Policy in Mental Health and Mental Health Services Research. $42,5,533-544$

Petty J (2017) Emotion work in qualitative research: interviewing parents about neonatal care. Nurse Researcher. 25, 3, 26-30.

Radenkovic D, Kotecha S, Patel S et al (2016) Improving maternal confidence in neonatal care through a checklist intervention. BMJ Quality Improvement Reports. 5, 1.

Riessman C, Speedy I (2007) Narrative inquiry in the psychotherapy professions: a critical review. In Clandinin DJ (Ed) Handbook of Narrative Inquiry: Mapping a Methodology. Sage, Thousand Oaks CA, 426-456

Roberts G, Cheong J (2014) Long-term growth and general health for the tiniest or most immature infants. Seminars in Fetal \& Neonatal Medicine. $19,2,118-124$

Sisson H, Jones C, Williams R et al (2015) Metaethnographic synthesis of fathers' experiences of the neonatal intensive care unit environment during hospitalization of their premature infants Journal of Obstetric, Gynecologic, and Neonatal Nursing. 44, 4, 471-480.

Smith V, Young S, Pursley D et al (2009) Are families prepared for discharge from the NICU? Journal of Perinatology. 29, 9, 623-629.

Sneath N (2009) Discharge teaching in the NICU: are parents prepared? An integrative review of parents' perceptions. Neonatal Network. 28, 4, 237-246.

Spinelli M, Frigerio A, Montali L et al (2016) 'I still have difficulties feeling like a mother': the transition to motherhood of preterm infants mothers. Psychology \& Health. 31, 2, 184-204.

Squire C, Davis M, Esin C et al (2014) What Narrative Research? Bloomsbury, London.
Staniszewska S, Brett J, Redshaw M et al (2012) The POPPY study: developing a model of family-centred care for neonatal units. Worldviews on EvidenceBased Nursing. 9, 4, 243-255.

Strauss A (1987) Qualitative Analysis for Social Scientists. Cambridge University Press, New York NY.

Strauss A, Corbin J (1998) Basics of Qualitative Research: Techniques and Procedures for Developing Grounded Theory. Second edition. Sage, Newbury Park CA

Toral-López I, Fernández-Alcántara M, GonzálezCarrión P et al (2016) Needs perceived by parents of preterm infants: integrating care into the early discharge process. Journal of Pediatric Nursing 31, 2, e99-e108.

Walsh M, Bell E, Kandefer S et al (2017) Neonatal outcomes of moderately preterm infants compared to extremely preterm infants. Pediatric Research. $82,2,297-304$.

Whittingham K, Boyd R, Sanders M et al (2014) Parenting and prematurity: understanding parent experience and preferences for support. Journal of Child and Family Studies. 23, 6, 1050-1061

World Health Organization (2012) Country Data and Rankings for Preterm Birth. WHO, Geneva. who.int/ pmnch/media/news/2012/201204 borntoosoon countryranking.pdf (Last accessed: 6 June 2018.)

World Health Organization (2018) Preterm Birth. WHO, Geneva. who.int/news-room/fact-sheets/ detail/preterm-birth (Last accessed: 6 June 2018.) 